\title{
Preface: aquatic homogenocene-understanding the era of biological re-shuffling in aquatic ecosystems
}

\author{
Andre Andrian Padial · Jean Ricardo Simões Vitule $\cdot$ Julian D. Olden
}

Accepted: 9 September 2020/Published online: 29 September 2020

(C) Springer Nature Switzerland AG 2020

Human impacts on atmospheric, geologic, hydrologic, biospheric, and other earth system processes have ushered in a new ecological era termed the 'Anthropocene' (Crutzen, 2002). As a consequence, overwhelming anthropogenic changes to ecosystems, including human-mediated mass extinction and invasion events, are now the focus of considerable ecological research. Initially introduced by Charles Elton in the classic book 'The Ecology of Invasions by Animals and Plants' (see Chapter 8 of the new edition of the book; Elton, 2020), McKinney \& Lockwood (1999) proposed the term 'biotic homogenization' (BH hereafter) to describe the process by which regionally distinct native communities are gradually

Guest editors: André A. Padial, Julian D. Olden \& Jean R. S. Vitule / The Aquatic Homogenocene

A. A. Padial ( $\square)$

Laboratório de Análise e Síntese em Biodiversidade, Departamento de Botânica. Programa de Pós-graduação em Ecologia e Conservação e Programa de Pós-graduação em Botânica, Universidade Federal do Paraná, Curitiba, PR, Brazil

e-mail: aapadial@gmail.com

\section{A. A. Padial}

Programa de Pós-graduação em Ecologia de Ambientes

Aquáticos Continentais, Núcleo de Pesquisa em

Limnologia, Ictiologia e Aquicultura (Nupelia),

Universidade Estadual de Maringá, Maringá,

PR, Brazil replaced by locally expanding, cosmopolitan, nonnative communities. The more connected we are as a society, the more likely we are to witness biotic homogenization and the ensuing ecological and evolutionary consequences (Olden et al., 2004), which defines the ecological era of the Homogenocene (also called Homogonece).

Despite considerable investigation into the patterns of $\mathrm{BH}$, there still exist many gaps in our taxonomic and geographic understanding, as well as uncertainties associated with the choice of analytical approaches (Olden et al., 2018). These knowledge gaps led us to organize the Special Issue 'Aquatic Homogenocene', where we sought to assemble a collection of studies from different regions of the world that encompassed a broad taxonomic breadth. The present issue contains 13 papers that deploy different approaches to examine

\footnotetext{
J. R. S. Vitule

Laboratório de Ecologia e Conservação (LEC),

Departamento de Engenharia Ambiental, Setor de

Tecnologia, Universidade Federal do Paraná, Curitiba, PR, Brazil
}

\section{J. D. Olden}

School of Aquatic and Fishery Sciences, University of Washington, Seattle, WA, USA 
biotic homogenization in an array of aquatic taxonomic groups (fish, macroinvertebrates, zooplankton, phytoplankton, and macrophyte) and geographic locations (Brazil, United States, Finland, China and South Africa). We hope that you enjoy the papers published in this special issue and feel motivated to further the study of the Aquatic Homogenocene.

Temporal scales by which $\mathrm{BH}$ has been investigated vary substantially. Past investigations of $\mathrm{BH}$ have largely focused on reconstructed species pools from published lists of native, extinct, and/or nonnative species, thus limiting comparisons to be made between some "historical" baseline and the present day (Rosenblad \& Sax, 2017). In this special issue, Jia et al. (2020) used data from a 50-year period; Brito et al. (2020) and Lindholm et al. (2020) examined data over a 70-year period; Kirk et al. (2020) leveraged historical data starting in the 1890's; and Peoples et al. (2020) used an estimation of original fish fauna in North America before European colonization. One paper examined patterns of community composition before and after major dam construction (Daga et al., 2020), and other 5 papers used data from c. 10-20 years, coinciding with popularization of longterm ecological programs and standard ecological assessments. Two contributions used a space-for-time substitution by comparing beta diversity between communities with and without occurrence of invasive crayfish species (Larson \& Pool, 2020) and before and after the biological control of a major invasive macrophyte (Coetzee et al., 2020). The majority of the studies found evidence for $\mathrm{BH}$, suggesting its pervasiveness across geographical regions and taxonomic groups.

In a review of the literature, Olden et al. (2018) highlighted that previous research has focused predominantly on taxonomic homogenization, whereas few studies have addressed functional and phylogenetic facets of this phenomenon. This special issue helped to fill this knowledge gap. Ten of the 13 papers addressed some aspect of functional diversity, and a single paper simultaneously examined taxonomic, functional, and phylogenetic diversity (Jia et al., 2020). We believe that further investigation of the phylogenetic aspects of $\mathrm{BH}$ is warranted.

All studies reported consistent evidence for $\mathrm{BH}$, with the exception of Lindholm et al. (2020) who found little change in indicators of functional similarity of macrophytes among 28 boreal lakes between the 1950s (1947-1951) and present day (2017). In the latter study, the authors highlighted that only modest environmental changes in boreal areas likely resulted in small community change over time. Even so, they raised a number of important issues. Ecological relationship between functional composition and environment differed among periods, suggesting that not only biodiversity similarity should be investigated. They further reported a weak association between environmental change and functional richness, despite the fact that individual traits became more rare or common over time. The results of Lindholm et al. (2020) point to the need to investigate the homogenization of ecological networks, as well as the simplification of community-environment relationships.

Spatial scales of investigation vary extensively, with studies quantifying $\mathrm{BH}$ across a broad range of spatial scales, spanning local to continental or global extents (Olden et al., 2018). The importance of spatial scale was focus of several studies. At local scales, human impacts may manifest in both $\mathrm{BH}$ and differentiation. For instance, Daga et al. (2020) demonstrated taxonomic and functional homogenization among South Brazilian hydrographic basins but variable patterns within ecoregions, in which taxonomic differentiation was more evident. At larger spatial scales, Larson \& Pool (2020) demonstrated conspicuous homogenization of crayfish faunas for major hydrographic basins across the USA, and Kirk et al. (2020) showed that the magnitude of fish faunal homogenization increased with spatial scale in the Great Plains-Rocky Mountain region of the USA. The latter study also highlighted that human-made reservoirs led to homogenization at intermediate scales, a pattern also supported by Daga et al. (2020). Using a different approach for macroinvertebrate communities in US praire-pothole wetlands, McLean et al. (2020) also suggested that larger 'landscape-level' scale experienced $\mathrm{BH}$ even though man-induced formation of lakes at local scales contributed to beta diversity. McLean et al. (2020) also contributed to a better understanding of $\mathrm{BH}$ phenomenon by investigating patterns using turnover and nestedness, two indexes that better describe beta diversity patterns (Baselga, 2010).

In a large scale, Peoples et al. (2020) reported the clearest evidence for BH across the eastern US, with an estimated fish faunal homogenization of $34 \%$ mean 
increase in pairwise community similarity. Their study comprised the longer time spam considering they used fauna dataset estimated before European settlements in America. In support of previous fish homogenization studies (e.g., Olden et al., 2008; Liu et al., 2017), these authors reported that extirpations of native species contributed little to observed changes in regional species similarity, whereas non-native species played a much more dominant role by leading to changes in composition and richness. Human activities were the underlying causes of $\mathrm{BH}$ across watersheds, and biotic resistance seems to decrease invasions, reducing the strength of $\mathrm{BH}$.

In the sole paper addressing simultaneously taxonomic, functional and phylogenetic facets of biodiversity, Jia et al. (2020) suggested that the homogenization of functional and phylogenetic components were strongest for the ichthyofauna of Yellow River, China. They demonstrated that despite increases in alpha diversity, beta diversity decreased over time (in agreement with Peoples et al., 2020), which reinforces that biodiversity should be used cautiously as an indicator of environmental wealth (Vellend, 2020). Related to the abovementioned idea, Simões et al. (2020) emphasized the complexity of the $\mathrm{BH}$ phenomenon, given that taxonomic and functional diversity of Northeast and South Brazilian cladocerans may lead to different conclusions. The authors also demonstrated potential thresholds in environmental disturbance that may lead to functional simplification. In another paper, Pineda et al. (2020) compared the 19-year trajectory of phytoplankton in dammed and non-dammed regions of a Southern Brazilian floodplain, and demonstrated that the loss in functional groups may lead to cascade effects where BH causes degradation of ecosystem processes such as nutrient flux due to the shifts in phytoplankton functional composition. Taken together, papers addressing functional diversity indicate that this aspect of $\mathrm{BH}$ is critical to explore further.

A unifying outcome of all the studies is that biological change is not unidirectional: transition phases between $\mathrm{BH}$ and biotic differentiation are common. Brito et al. (2020) reported a shift from homogenization to differentiation in fisheries at both within and among hydrographic basins in semi-arid Northeast Brazil, indicating that invasive species may lead to increasing dissimilarity after strong impacts caused by damming, stocking programs, and non- native fish cultures. Biotic differentiation resulting from invasive species is most likely at local scales. Magalhães et al. (2020) showed that changes in streams close to aquaculture facilities initially led to $\mathrm{BH}$ of fish faunas in Southeast Brazil and then to biotic differentiation caused by the colonization pressure from a variety of the species cultivated for aquarium trade and local native species extirpations.

In another study, Coetzee et al. (2020) showed that the invasive macrophyte water lettuce caused $\mathrm{BH}$ in associated macroinvertebrates, by comparing nearby sites with and without the invasive plant. But after applying a biological control agent to reduce water lettuce abundance, macroinvertebrates were found to increase in diversity leading to biotic differentiation. In agreement with all studies, Coetzee et al. (2020) not only demonstrated the fundamental role of invasive leading to $\mathrm{BH}$, but also highlighted how $\mathrm{BH}$ can be "reversed" through the active control of invasive species. In this case, water lettuce is an ecosystem engineer that plays an overwhelming role in providing habitat structure and shaping nutrient fluxes (Kovalenko et al., 2012; Ribaudo et al., 2018). The identification of transitions phases indicates that longterm monitoring should be a strategy adopted by researchers and decision-makers (see McLean et al., 2020). In this sense, Zeni et al. (2020) reinforced the pattern that past environmental changes in streams agro-ecosystems promoted persistence generalist fish species, and that stochasticity better explains local species loss after the persistent phenomenon. According to the authors, preservation and restoration of local patches could mitigate effects by enhancing environmental heterogeneity and dispersal, consequently keeping beta diversity and avoiding local-scale BH.

In summary, the collection of studies published in the special issue Aquatic Homogenocene provides important additional insight in the patterns and drivers of $\mathrm{BH}$ in aquatic ecosystems and points to critical areas requiring additional investigation. Finally, we provide a roadmap that should be considered for future research in BH (Fig. 1). This scheme summarizes issues that we considered as important when addressing $\mathrm{BH}$, given the current status of knowledge. Our hope is that future research continues to fill knowledge gaps that better help society slow or cope with the era of biological re-shuffling in aquatic ecosystems. 


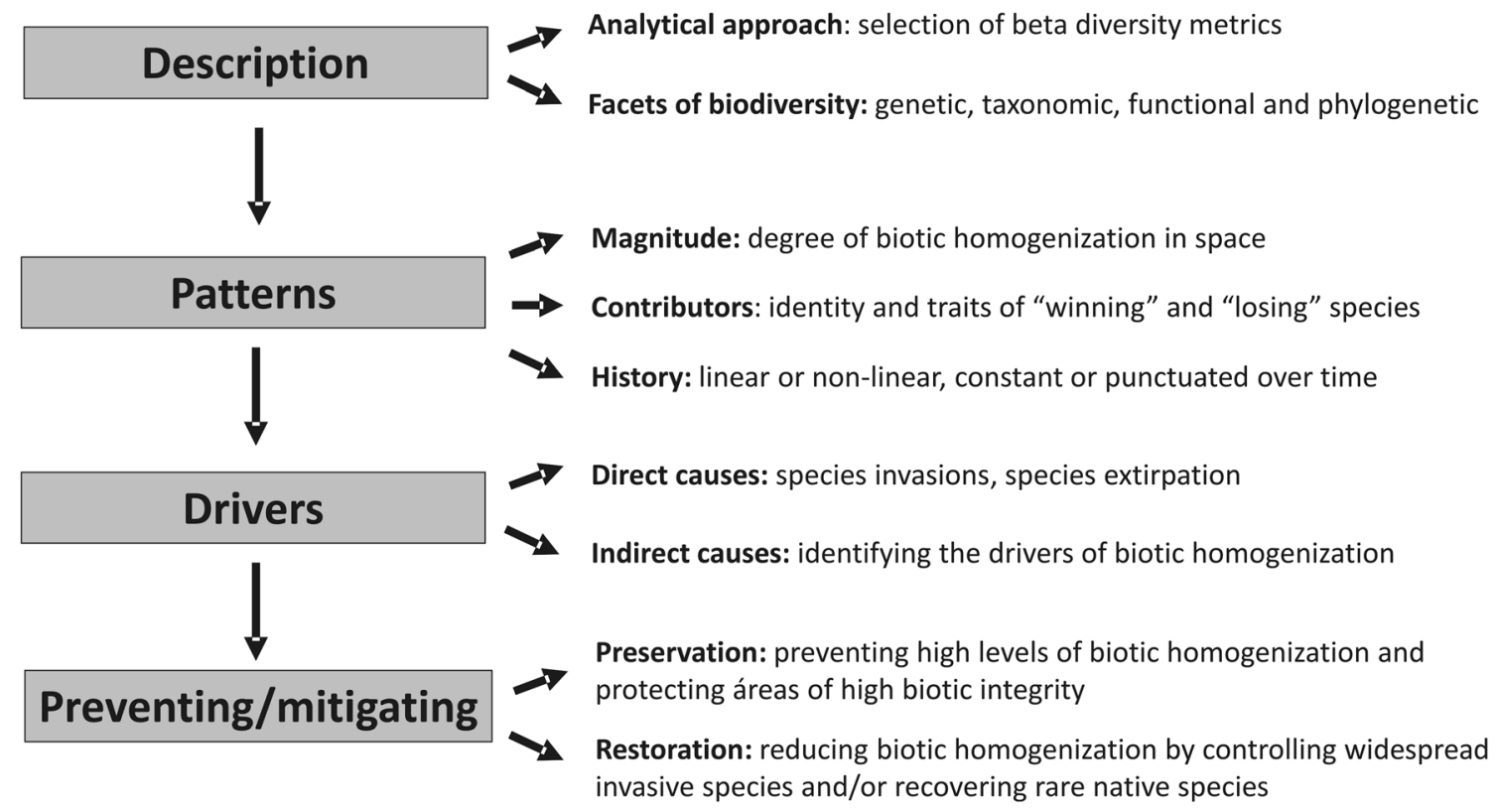

Fig. 1 Roadmap for biotic homogenization research

\section{References}

Crutzen, P., 2002. Geology of mankind. Nature 415: 23.

Baselga, A., 2010. Partitioning the turnover and nestedness components of beta diversity. Global Ecology and Biogeography 19: 134-143.

Brito, M. F. G., V. S. Daga \& J. R. S. Vitule, 2020. Fisheries and biotic homogenization of freshwater fish in the Brazilian semiarid region. Hydrobiologia, this issue. https://doi.org/ 10.1007/s10750-020-04236-8

Coetzee, J., S. Langa, S. Motitsoe \& M. Hill, 2020. Biological control of water lettuce, Pistia stratiotes L., facilitates macroinvertebrate biodiversity recovery: a mesocosm study. Hydrobiologia, this issue. https://doi.org/10.1007/ s10750-020-04369-w

Daga, V. S., J. D. Olden, E. A. Gubiani, P. A. Piana, A. A. Padial \& J. R. S. Vitule. Scale-dependent patterns of fish faunal homogenization in Neotropical reservoirs. Hydrobiologia, this issue. https://doi.org/10.1007/s10750-019-04145-5

Elton, C. S., 2020. The Ecology of Invasions by Animals and Plants, with Contibutions by Daniel Simberloff and Anthony Ricciardi, 2nd ed. Springer, Cham.

Jia, Y., M. J. Kennard, Y. Liu, X. Sui, K. Li, G. Wang \& Y. Chen, 2020. Human disturbance and long-term changes in fish taxonomic, functional and phylogenetic diversity in the Yellow River, China. Hydrobiologia, this issue. https://doi. org/10.1007/s10750-020-04244-8

Kirk, M. A., B. M. Maitland \& F. J. Rahel, 2020. Spatial scale, reservoirs and nonnative species influence the homogenization and differentiation of Great Plains-Rocky Mountain fish faunas. Hydrobiologia, this issue. https://doi. org/10.1007/s10750-019-04129-5.
Kovalenko, K. E., S. M. Thomaz \& D. M. Warfe, 2012. Habitat complexity: approaches and future directions. Hydrobiologia 685: 1-17.

Larson, E. R. \& T. K. Pool, 2020. Biological invasions drive biotic homogenization of North American crayfishes. Hydrobiologia, this issue. https://doi.org/10.1007/s10750019-04164-2.

Lindholm, M., J. Alahuhta, J. Heino, J. Hjort \& H. Toivonen, 2020. Changes in the functional features of macrophyte communities and driving factors across a 70 -year period. Hydrobiologia, this issue. https://doi.org/10.1007/s10750019-04165-1.

Liu, C., D. He, Y. Chen \& J. D. Olden, 2017. Species invasions threaten the antiquity of China's freshwater fish fauna. Diversity and Distributions 23: 556-566.

Magalhães, A. L. B., V. S. Daga, L. A. V. Bezerra, J. R. S. Vitule, C. M. Jaconi \& L. G. M. Silva, 2020. All the colors of the world: biotic homogenization-differentiation dynamics of freshwater fish communities on demand of the Brazilian aquarium trade. Hydrobiologia, this issue. https:// doi.org/10.1007/s10750-020-04307-w.

McKinney, M. L. \& J. L. Lockwood, 1999. Biotic homogenization: a few winners replacing many losers in the next mass extinction. Trends in Ecology \& Evolution 14: 450-453.

McLean, K. I., D. M. Mushet, J. N. Sweetman, M. J. Anteau \& M. T. Wiltermuth, 2020. Invertebrate communities of prairie-pothole wetlands in the age of the aquatic homogenocene. Hydrobiologia, this issue. https://doi.org/10. 1007/s10750-019-04154-4.

Olden, J. D., N. L. Poff, M. R. Douglas, M. E. Douglas \& K. D. Fausch, 2004. Ecological and evolutionary consequences of biotic homogenization. Trends in Ecology \& Evolution 19: 18-24. 
Olden, J. D., M. J. Kennard \& B. J. Pusey, 2008. Species invasions and the changing biogeography of Australian freshwater fishes. Global Ecology and Biogeography 17: 25-37.

Olden, J. D., L. Comte \& X. Giam, 2018. The Homogocene: a research prospectus for the study of biotic homogenisation. NeoBiota 37: 23-36.

Peoples, B. K., A. J. S. Davis, S. R. Midway, J. D. Olden \& L. Stoczynski, 2020. Landscape-scale drivers of fish faunal homogenization and differentiation in the eastern United States. Hydrobiologia, this issue. https://doi.org/10.1007/ s10750-019-04162-4.

Pineda, A., P. Iatskiu, S. Jati, A. C. M. Paula, B. F. Zanco, C. C. Bonecker, G. A. Moresco, L. A. Ortega, Y. R. Souza \& L. C. Rodrigues, 2020. Damming reduced the functional richness and caused the shift to a new functional state of the phytoplankton in a subtropical region. Hydrobiologia, this issue. https://doi.org/10.1007/s10750-020-04311-0.

Ribaudo, C., J. Tison-Rosebery, D. Buquet, G. Jan, A. Jamoneau, G. Abril, P. Anschutz \& V. Bertrin, 2018. Invasive aquatic plants as ecosystem engineers in an Oligo-Mesotrophic Shallow Lake. Frontiers in Plant Science 9: 1781.
Rosenblad, K. C. \& D. F. Sax, 2017. A new framework for investigating biotic homogenization and exploring future trajectories: oceanic island plant and bird assemblages as a case study. Ecography 40: 1040-1049.

Simões, N. R., L. S. M. Braghin, G. A. V. Duré, J. S. Santos, S. L. Sonoda \& C. C. Bonecker, 2020. Changing taxonomic and functional $\beta$-diversity of cladoceran communities in Northeastern and South Brazil. Hydrobiologia, this issue. https://doi.org/10.1007/s10750-020-04234-w.

Vellend, M., 2020. The biodiversity conservation paradox. American Naturalist 105: 94-101. https://doi.org/10.1511/ 2017.105.2.94.

Zeni, J. O., D. J. Hoeinghaus, C. A. Roa-Fuentes \& L. Casatti, 2020. Stochastic species loss and dispersal limitation drive patterns of spatial and temporal beta diversity of fish assemblages in tropical agroecosystem streams. Hydrobiologia, this issue. https://doi.org/10.1007/s10750-02004356-1.

Publisher's Note Springer Nature remains neutral with regard to jurisdictional claims in published maps and institutional affiliations. 